\title{
PENGARUH GREEN MARKETING MIX TERHADAP MINAT BELI PRODUK LOVE BEAUTY AND PLANET DI JAKARTA
}

\author{
Dwi Oktaviani, Rodhiah
}

Universitas Tarumanagara (UNTAR) Jakarta, Indonesia

Email: dwi.115170132@stu.untar.ac.id,rodhiah@fe.untar.ac.id

\begin{abstract}
Abstrak
Tujuan dari penelitian ini adalah untuk mengetahui pengaruh Green Marketing Mix yang terdiri dari Green Product, Green Price, Green Place dan Green Promotion terhadap minat beli konsumen pada produk Love Beauty and Planet. Penelitian ini menggunakan desain penelitian Deskriptif. Pengambilan sampel dilakukan dengan metode Purposive sampling dengan jumlah sampel sebanyak 100 responden yang merupakan konsumen Love Beauty and Planet di Jakarta. Data dikumpulkan dengan menyebarkan kuesioner secara online (Google From). Analisis data yang digunakan adalah Structural Equation Model (SEM) dengan menggunakan alat analisis data yaitu SmartPLS. Hasil dari penelitian menunjukkan bahwa dari Green Marketing Mix hanya Green Product dan Green Price yang mempengaruhi minat beli konsumen sedangkan Green Place dan Green Promotion tidak mempengaruhi minat beli konsumen Love Beauty and Planet di Jakarta. Dari hasil penelitian tersebut dapat disimpulkan bahwa minat beli konsumen Love Beauty and Planet di Jakarta tidak dipengaruhi oleh promosi dan tempat pendistribusian produk Love Beauty And Planet.
\end{abstract}

Kata Kunci: green product; green price; green place; green promotion; minat beli

\section{Abstract}

The purpose of this study was to determine the effect of the Green Marketing Mix consisting of Green Product, Green Price, Green Place and Green Promotion on consumer purchase intention for Love Beauty and Planet products. This study uses a descriptive research design. Sampling was done by purposive sampling method with a total sample of 100 respondents who are consumers of Love Beauty and Planet in Jakarta. Data was collected by distributing online questionnaires (Google From). The data analysis used is the Structural Equation Model (SEM) and using a data analysis tool SmartPLS. The results of this study are from the Green Marketing Mix only Green Product and Green Price that affect consumer purchase intention, while Green Place and Green Promotion do not affect consumers purchase intention in Love Beauty and Planet in Jakarta. From the results of the research, it was concluded that the purchase intention of Love Beauty and Planet consumers in Jakarta was not influenced by the promotion and distribution of Love Beauty And Planet products.

Keywords: green product; green price; green place; green promotion; purchase intention

\begin{tabular}{ll}
\hline How to cite: & Oktaviani, Dwi, Rodhiah (2021) Pengaruh Green Marketing Mix Terhadap Minat Beli Konsumen \\
& Love Beauty and Planet di Jakarta, Syntax Idea, 3(7). https://doi.org/10.36418/syntax-idea.v3i7.1306 \\
E-ISSN: & $2684-883 X$ \\
Published by: & Ridwan Institute
\end{tabular}




\section{Pendahuluan}

Saat ini, masyarakat sadar mengenai isu permasalahan lingkungan yang meningkat pesat dan berpengaruh pada kehidupan sehari-hari maupun pada masa depan. Isu mengenai permasalahan lingkungan, pencemaran lingkungan dan kelestarian lingkungan menjadi permasalahan utama dunia. Masalah lingkungan yang muncul seperti pemanasan global dan polusi yang secara langsung maupun tidak langsung terjadi karena aktivitas sehari-hari dari masyarakat sendiri, contohnya seperti sampah sampah yang dihasilkan sulit dan lama untuk terurai, bahan-bahan yang digunakan untuk kehidupan sehari-hari mengandung kimia yang berbahaya bagi lingkungan. (Tiwari, Tripathi, Srivastava, \& Yadav, 2011) berpendapat bahwa perusahaan yang menerapkan strategi green marketing akan menetapkan harga yang lebih tinggi dibandingkan dengan harga produk pesaing. Kesuksesan akan penjualan green product didukung oleh green place dan green promotion yang tepat dilakukan oleh perusahaan Menurut (Pathak, 2017), pemasaran hijau adalah pemasaran yang mengutamakan lingkungan. Semua aktivitas yang ditentukan untuk memuaskan kebutuhan dan keinginan manusia serta memastikan lingkungan tidak terdapat polusi yang membahayakan. (Mahmoud, T. O., Ibrahim, S. B., Ali, A. H., \& Bleady, 2017) menyatakan bahwa Green Marketing Mix berpengaruh positif dan signifikan terhadap minat beli konsumen. Menurut (Arslan \& Zaman, 2015) Minat pembelian dapat didefinisikan sebagai kemungkinan konsumen akan membeli produk atau layanan di masa depan. Minat membeli yang positif mendorong ke konsumen untuk tindakan pembelian aktual atau negatif minat beli menahan konsumen untuk tidak beli itu. Peningkatan minat membeli berarti peningkatan kemungkinan pembelian.

Dalam bidang usaha bisnis, perubahan yang mulai mengarahkan usaha dengan pendekatan aktivitas bisnis berbasis kelestarian lingkungan. Banyak perusahaan sudah mulai memikirkan efek samping dari produk yang dihasilkan atau bisnis yang sedang dijalankan. Perusahaan memanfaatkan isu ini untuk mencari keuntungan dan memenuhi keinginan konsumen akan produk yang Eco-label, Eco-brand, dan environmental advertisement. Perusahaan mulai berahli menggunakan bahan baku yang ramah lingkungan serta menggunakan kemasan yang mudah terurai, ramah lingkungan dan tidak berbahaya bagi lingkungan. Konsep green marketing merupakan suatu alternatif yang dapat digunakan perusahaan dalam melaksanakan aktivitas pemasaran dengan memanfaatkan sumber daya yang terbatas secara efisien dan efektif. Love Beauty and Planet merupakan salah satu dari beberapa perusahaan yang menerapkan konsep Green Marketing Mix pada produknya.

Dilihat dari penelitian terdahulu yang dilakukan oleh (Mahmoud, T. O., Ibrahim, S. B., Ali, A. H., \& Bleady, 2017) yang meneliti pengaruh Green Marketing Mix terhadap minat beli konsumen dengan hasil yang menyatakan bahwa Green Marketing Mix berpengaruh terhadap minat beli konsumen. Hal ini terdapat kesenjangan dengan penelitian yang dilaukan oleh (Karunarathna, Bandara, Silva, \& De Mel, 2020) dalam penelitiannya menyatakan bahwa Green Product,Green Price, dan Green Promotion berpengaruh terhadap minat beli, namun Green Place tidak berpengaruh terhadap minat 
beli konsumen. Oleh karena itu penelitian ini merupakan replikasi dari penelitian terdahulu yang membahas Green Marketing mix yang terdiri dari, Green Product, Green Price, Green place dan Green Promotion mana yang berpengaruh terhadap minat beli produk Love Beauty and Planet.

\section{Minat Beli}

Minat beli merupakan pernyataan mental konsumen yang merefleksikan rencana pembelian suatu produk dengan merek tertentu (Penitasari, 2017). Menurut (Phillip \& Keller, 2012), minat beli konsumen adalah seberapa besar kemungkinan konsumen untuk membeli suatu merek atau berpindah dari satu merek ke merek lainnya. Menurut (Phillip \& Keller, 2012), minat beli dapat diidentifikasikan dengan indikator-indikator sebagai berikut:

a. Minat Transaksional, yaitu kecenderungan seseorang untuk membeli produk.

b. Minat Referensial, yaitu kecenderungan seseorang untuk mereferensikan produk kepada orang lain.

c. Minat Preferensial, yaitu minat yang menggambarkan perilaku seseorang yang memiliki preferensi utama pada produk tersebut. Preferensi ini hanya dapat diganti jika terjadi sesuatu dengan produk preferensinya.

d. Minat Eksploratif, yaitu minat ini menggambarkan perilaku seseorang yang selalu mencari informasi mengenai produk yang diminatinya dan mencari informasi untuk mendukung sifat-sifat positif dari produk tersebut

\section{Green Product}

Menurut (Kumar \& Ghodeswar, 2015) produk hijau (Green Product) diartikan sebagai "produk yang dulu diproduksi menggunakan bahan bebas racun dan tindakan ramah lingkungan, dan yang mana disertifikasi seperti itu oleh organisasi yang diakui.

\section{Green Price}

Menurut (Tiwari et al., 2011) berpendapat bahwa perusahaan yang menerapkan strategi green marketing akan menetapkan harga yang lebih tinggi dibandingkan dengan harga produk pesaing. (Hashem \& Al-Rifai, 2011), the definition of green price:"Green price refers to the price specified in the light of company's policies with regard to environmental consideration imposed by rules and company instructions or its initiatives in this regard.

\section{Green Place}

Menurut (Queensland Government, 2002) mengemukakan perusahaan yang ingin mencapai kesuksesan dalam penjualan produk yang ramah lingkungan seharusnya memposisikan produknya secara luas di pasar sehingga dapat dikenali. Tempat hijau adalah tentang mengelola logistik untuk dipotong menurunkan emisi transportasi, dengan demikian berlaku bertujuan untuk mengurangi jejak karbon menurut (Shil, 2012).

\section{Green Promotion}

Penjualan produk hijau yang cerdas akan dapat menekankan kredibilitas produk yang ramah lingkungan dengan menggunakan sustainable marketing dan juga 
menggunakan alat praktek komunikasi dikemukakan oleh (Queensland Government, 2002). Tujuan dari iklan hijau adalah untuk mempengaruhi perilaku pembelian konsumen dengan mendorong mereka untuk membeli produk yang tidak merusak lingkungan dan mengarahkan minat mereka ke hal yang positif konsekuensi dari perilaku pembelian mereka, untuk diri mereka sendiri serta lingkungan menurut (Rahbar \& Wahid, 2011).

\section{Kaitan antara Green Product dengan Minat Beli}

Menurut (Karunarathna et al., 2020) dengan hasil bahwa Green product memiliki pengaruh terhadap minat beli dengan referensi khusus ke supermarket di Srilanka dengan perilaku lingkungan konsumen sebagai mediasi. Pada penelitian yang dilakukan oleh (Mahmoud, T. O., Ibrahim, S. B., Ali, A. H., \& Bleady, 2017) mengenai pengaruh Green Marketing Mix terhadap minat beli menyatakan bahwa Green Product berpengaruh positif dengan minat beli. Dalam penelitian yang dilakukan oleh (Mahmoud, T. O., Ibrahim, S. B., Ali, A. H., \& Bleady, 2017) menyatakan bahwa terdapat pengaruh positif antara Green Product dengan minta beli konsumen.

\section{Kaitan antara Green Price Dengan Minat Beli}

Penelitian yang dilakukan oleh (Musa, Mansor, \& Musa, 2020) mengenai pengaruh Green Marketing Mix terhadap Minat beli Produk ramah lingkungan, menunjukan hasil bahwa terdapat pengaruh yang positif antara Green Price dengan Minat beli dengan nilai p 0,000 lebih rendah dari nilai alpha 0,05. Menurut (Mahmoud, T. O., Ibrahim, S. B., Ali, A. H., \& Bleady, 2017) pada penelitiannya menyatakan bahwa Green price berpengaruh positif dengan Minat Beli dengan nilai ( $\beta=0.119, \mathrm{p}<0.05$ ). Pada penelitian yang dilakukan oleh (Mahmoud, T. O., Ibrahim, S. B., Ali, A. H., \& Bleady, 2017) mengenai pengaruh Green Marketing Mix terhadap minat beli menyataan bahwa Green Price (X2) berpengaruh positif dengan Minat beli dengan hasil $(\beta=0.119, \mathrm{p}<0.05)$.

\section{Kaitan antara green place Dengan Minat Beli}

Menurut (Mahmoud, T. O., Ibrahim, S. B., Ali, A. H., \& Bleady, 2017) pada penelitiannya menyatakan bahwa terdapat pengaruh positif antara Green Place dengan minat beli konsumen dengan nilai $(\beta=0.183, \mathrm{p}<0.01)$. Pada penelitian yang dilakukan oleh (Musa et al., 2020) mengenai pengaruh Green Marketing Mix terhadap Minat beli Produk ramah lingkungan, menunjukan hasil bahwa terdapat pengaruh yang positif antara Green Place dengan minat beli dengan nilai p 0,000 yang lebih rendah dari nilai alpha 0,0. Dalam penelitian mengenai Pengaruh Green Marketing Mix pada minat membeli dengan Pengetahuan Lingkungan sebagai Mediasi yang dilakukan oleh (Mahmoud, T. O., Ibrahim, S. B., Ali, A. H., \& Bleady, 2017) menyatakan bahwa terdapat pengaruh positif antara Green Place dengan minta beli dengan nilai $(\beta=0.314, p<0.01)$.

\section{Kaitan Antara Green Promotion Dengan Minat Beli}

Menurut (Mahmoud, T. O., Ibrahim, S. B., Ali, A. H., \& Bleady, 2017) pada penelitiannya menyatakan bahwa terdapat pengaruh positif antara Green Promotion 
dengan minat beli konsumen dengan nilai $(\beta=0.314, \mathrm{p}<0.01)$. Pada penelitian yang dilakukan oleh (Musa et al., 2020) mengenai pengaruh Green Marketing Mix terhadap Minat beli Produk ramah lingkungan, menunjukan bahwa terdapat pengaruh yang positif antara Green Promotion dengan minat beli dengan nilai p 0,000 yang lebih rendah dari nilai alpha 0,05 dan $\beta=0.684$. Dari penelitin yang dilakukan oleh (Karunarathna et al., 2020) dengan hasil bahwa Green Promotion memiliki pengaruh terhadap minat beli (Y), dilihat dari nilai signifikan $0.014<0.05$

Tujuan dilakukannya penelitian ini adalah untuk mengetahui faktor apa saja dari Green Marketing Mix yang berpengaruh positif dan signifikan terhadap Minat beli produk Love Beauty and Planet di Jakarta.

Penelitian ini diharapkan dapat membuktikan apakah terdapat pengaruh dari Green Marketing Mix terhadap minat beli produk Love Beauty and Planet di Jakarta. (1.) Penelitian ini diharapkan dapat menjadi bahan pertimbangan dan masukan bagi perusahaan dalam menetapkan kebijakan dan strategi untuk mengembangkan usaha bisnis mereka. (2.) Penelitian ini diharapkan dapat memberikan masukan serta dapat menjadi bahan acuan atau referensi bagi penelitian selanjutnya

\section{Metode Penelitian}

Pada penelitian ini desain penelitian yang digunakan adalah desain penelitian kuantitatif deskriptif. Populasi dalam penelitian ini adalah konsumen produk Love Beauty and Planet di daerah Jakarta yang mengetahui atau sudah pernah membeli produk Love Beauty and planet. Teknik pemilihan sampel pada penelitian ini adalah dengan Purposive Sampling, dengan jumlah responden sebanyak 100 orang. Data dianalisis menggunakan software Smart PLS dengan teknik analisis data structural equation model (SEM).

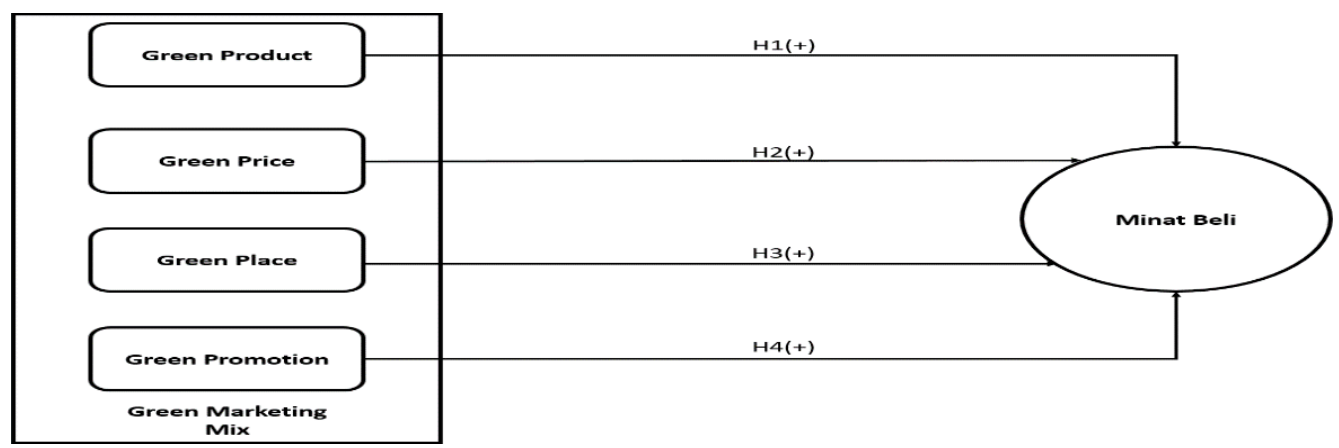

\section{Gambar 1 \\ Model Penelitian}

Hipotesis

H1: Green Product berpengaruh positif dan signifikan terhadap Minat Beli Konsumen

Love Beauty and Planet 
H2: Green Price berpengaruh positif dan signifikan terhadap Minat Beli Konsumen Love Beauty and Planet

H3: Green Place berpengaruh positif dan signifikan terhadap Minat Beli Konsumen Love Beauty and Planet

H4: Green promotion berpengaruh positif dan signifikan terhadap Minat Beli Konsumen Love Beauty and Planet

\section{Hasil dan Pembahasan}

\section{A. Hasil Penelitian}

\section{Validitas}

Penelitian ini menggunakan teknik analisis data SEM, peneliti telah mendapatkan hasil analisis validitas konvergen yaitu Average Variance Extracted (AVE) dan validitas diskriminan yaitu Heterotrait-Monotrait Ratio (HTMT).

\section{a. Validitas Konvergen}

Hasil analisis Averag Variance Extracted (Tabel 1) menunjukan bahwa setiap variabel memiliki nilai lebih dari $0.50(>0.50)$. Oleh karena itu variable yang digunakan pada penelitian ini telah memenuhi syarat dari validitas konvergen berdasarkan analisis Aveage Variance Extracted (AVE)

\section{Tabel 1}

\section{Hasil Analisis Validitas Konvergen}

\begin{tabular}{ll}
\hline Variabel & Average Variance Extracted \\
\hline Green Product & 0.677 \\
\hline Green Price & 1.000 \\
\hline Green Place & 0.680 \\
\hline Green Promotion & 0.656 \\
\hline Minat Beli & 0.777 \\
\hline
\end{tabular}

\section{b. Validitas Diskriminasi}

Hasil dari Heterotrait-Monotrait Ratio (Tabel 2) menunjukkan bahwa seluruh nilai pada setiap indikator sudah kurang dari $0.9(<0.9)$.

Tabel 2

Hasil Analisis Validitas Diskriminan

\begin{tabular}{lccccc}
\hline Variabel & $\begin{array}{c}\text { Green } \\
\text { Place }\end{array}$ & $\begin{array}{c}\text { Green } \\
\text { Price }\end{array}$ & $\begin{array}{c}\text { Green } \\
\text { Product Promotion }\end{array}$ & $\begin{array}{l}\text { Green } \\
\text { Beli }\end{array}$ \\
\hline Green Price & 0.514 & & & & \\
\hline Green Product & 0.597 & 0.352 & & & \\
\hline $\begin{array}{l}\text { Green } \\
\text { Promotion }\end{array}$ & 0.640 & 0.442 & 0.672 & & \\
\hline Minat Beli & 0.098 & 0.295 & 0.290 & 0.263 \\
\hline
\end{tabular}




\section{Reliabilitas}

\section{a. Reliabilitas Indikator}

Hasil dari analisis loading factor (Tabel 3) yang mengukur konstruk membuktikan bahwa setiap indikator variabel penelitian memiliki nilai lebih dari 0.6 (>0.6). Indikator yang digunakan untuk mengukur variabel dalam penelitian ini sudah reliabel dan dapat diandalkan. Pada analisis loading factor terdapat indicator yang memiliki nilai kurang dari 0.6, artinya indikator tersebut tidak reliabel, maka indicator tersebut dihapuskan. Indicator tersebut adalah Green Price1 dengan nilai (-0.121) dan Green Price2 dengan nilai ($0.325)$.

Tabel 3

Hasil Analisis Reliabilitas Indikator

\begin{tabular}{lccccc}
\hline \multicolumn{1}{c}{ Variabel } & $\begin{array}{c}\text { Green } \\
\text { Place }\end{array}$ & $\begin{array}{c}\text { Green } \\
\text { Price }\end{array}$ & $\begin{array}{c}\text { Green } \\
\text { Product }\end{array}$ & $\begin{array}{c}\text { Green } \\
\text { Promotion }\end{array}$ & $\begin{array}{c}\text { Minat } \\
\text { Beli }\end{array}$ \\
\hline Green Price & 0.514 & & & & \\
\hline Green Product & 0.597 & 0.352 & & & \\
\hline $\begin{array}{l}\text { Green } \\
\text { Promotion }\end{array}$ & 0.640 & 0.442 & 0.672 & & \\
\hline Minat Beli & 0.098 & 0.295 & 0.290 & 0.263 & \\
\hline
\end{tabular}

\begin{tabular}{|c|c|c|c|c|}
\hline $\begin{array}{c}\text { Green } \\
\text { Product }\end{array}$ & Green Price & Green Place & $\begin{array}{c}\text { Green } \\
\text { Promotion }\end{array}$ & Minat Beli \\
\hline GPD1 0.919 & & GPL1 0.780 & GPO1 0.845 & MB1 0.875 \\
\hline GPD2 0.794 & & GPL2 0.747 & GPO2 0.884 & MB2 0.881 \\
\hline GPD3 0.746 & GPR3 1.000 & GPL3 0.935 & GPO3 0.686 & $\begin{array}{ll}\text { MB3 } & 0.903 \\
\end{array}$ \\
\hline & & & & MB4 0.866 \\
\hline
\end{tabular}

\section{b. Reliabilitas Konsistensi Internal}

Hasil dari analisis composite reliability (Tabel 4) yang mengukur nilai reliabilitas dari suatu konstruk membuktikan bahwa setiap variabel penelitian memiliki nilai lebih dari 0.7. Indikator yang digunakan untuk mengukur variabel dalam penelitian ini sudah reliabel dan dapat diandalkan karena memiliki nilai lebih besar dari 0.7 .

Tabel 4

\begin{tabular}{lc}
\multicolumn{2}{c}{ Hasil Analisis Reliabilitas Konsistensi Internal } \\
\hline Variabel & Composite Reliability \\
\hline Green Product & 0.862 \\
\hline Green Price & 1.000 \\
\hline Green Place & 0.863 \\
\hline Green Promotion & 0.850 \\
\hline Minat Beli & 0.933 \\
\hline
\end{tabular}




\section{Hasil Analisis Multikoliniearitas}

Hasil analisis multikoliniearitas (Tabel 5) menguji apakah terdapat korelasi antar variabel didalam model regresi pada penelitian ini. Korelasi antar variabel dapat dikatakan baik karna memiliki nilai VIF kurang dari 5. Berdasarkan hasil uji, tidak terdapat multikolinearitas antar variabel bebas.

Tabel 5

Hasil analisis Multikoliniearitas

\begin{tabular}{lll}
\hline Variabel & \multicolumn{1}{l}{ Nilai } & Keterangan \\
\hline MB & & \\
& & \\
f(GPD,GPR,GPL,DP & VIF $=1.501$ & Tidak ada \\
O) GPD & VIF $=1.334$ & multikolinearitas \\
GP & VIF $=1.512$ & Tidak ada \\
R & VIF $=1.612$ & multikolinearitas \\
GP & & Tidak ada \\
L & & multikolinearitas \\
GP & & Tidak ada \\
O & & multikolinearitas \\
\hline
\end{tabular}

Keterangan

GPD $=$ Green product GPR $=$ Green Price GPL $=$ Green Place

$\mathrm{GPO}=$ Green Promotion

\section{Hasil Analisis Koefisien Determinasi $\left(\mathbf{R}^{2}\right)$}

\section{Tabel 6}

Hasil Analisis Koefisien Determinasi $\left(\mathbf{R}^{2}\right)$

\begin{tabular}{lll}
\hline Variabel & R Square & Keterangan \\
\hline Minat Beli & 0.165 & Kecil \\
\hline
\end{tabular}

\section{Hasil Analisis Predictive Relevance $\left(\mathbf{Q}^{2}\right)$}

Berdasarkan hasil analisis predictive relevance $\left(\mathrm{Q}^{2}\right)$ pada table 7 menjelaskan bahwa hubungan konstruk antar variabel yang diteliti dalampenelitian ini dianggap relevan untuk mengukur model penelitian karena memiliki nilai $\mathrm{Q}^{2}$ lebih besar dari $0(>0)$.

Tabel 7

Hasil analisis Predictive Relevance $\left(\mathbf{Q}^{2}\right)$

\begin{tabular}{ll}
\hline Variabel & $\mathrm{Q}^{2}$ \\
\hline Minat Beli & 0.107 \\
\hline
\end{tabular}




\section{Uji Hipotesis}

\section{Tabel 8}

Hasil Uji Hipotesis

\begin{tabular}{lll}
\hline Variabel & Nilai & Keterangan \\
\hline Green Product $\rightarrow$ Minat beli & $\beta: 0.294$ & Positif \\
& P-value $: 0.004$ & Signifikan \\
& $\mathrm{f}^{2}: 0.069$ & Kecil \\
\hline Green Price $\rightarrow$ Minat beli & $\beta: 0.237$ & Positif \\
& $\mathrm{P}$-value $: 0.026$ & Signifikan \\
& $\mathrm{f}^{2}: 0.050$ & Kecil \\
\hline Green Place $\rightarrow$ Minat beli & $\beta:-0.180$ & Negatif \\
& $\mathrm{P}$-value $: 0.123$ & Tidak Signifikan \\
& $\mathrm{f}^{2}: 0.026$ & Kecil \\
\hline Green Promotion $\rightarrow$ Minat beli & $\beta: 0.075$ & Positif \\
& $\mathrm{P}$-value $: 0.250$ & Tidak Signifikan \\
& $\mathrm{f}^{2}: 0.004$ & Kecil \\
\hline
\end{tabular}

\section{B. Pembahasan}

Berdasarkan hasil uji hipotesis pertama, green product memberikan pengaruh yang positif dan signifikan terhadap minat beli produk Love Beauty and Planet di Jakarta. Hal ini sesuai dengan penelitian sebelumnya (Mahmoud, T. O., Ibrahim, S. B., Ali, A. H., \& Bleady, 2017) yang menyatakan bahwa green product memiliki pengaruh yang positif dan signifikan terhadap minat beli konsumen. Dalam penelitian ini konsumen merasa bahwa produk yang digunakan merupakan produk yang ramah lingkungan dan dipercaya bahwa produk Love Beauty and Planet tidak berbahaya dan tidak merusak lingkungan. Dalam hasil uji hipotesis kedua didukung, dibuktikan dengan green price berpengaruh positif terhadap minat beli dan memberikan pengaruh yang signifikan terhadap minat beli konsumen Love Beauty and Planet. Dalam hal ini hasil penelitian sesuai dengan penelitian sebelumnya (Musa et al., 2020); (Mahmoud, T. O., Ibrahim, S. B., Ali, A. H., \& Bleady, 2017) yang menyatakan bahwa green price berpengaruh positif dan signifikan terhadap minat beli konsumen. Hasil uji hipotesis ketiga, green place berpengaruh negatif dan tidak signifikan terhadap minat beli konsumen Love Beauty and Planet di Jakarta. Hal ini tidak sesuai dengan penelitian yang dilakukan sebelumnya (Mahmoud, T. O., Ibrahim, S. B., Ali, A. H., \& Bleady, 2017) ;(Musa et al., 2020) yang menyatakan bahwa green place berpengaruh positif dan signifikan terhadap minat beli konsumen. Pernyataan ini tidak berlaku pada konsumen Love Beauty and Planet di Jakarta. Dalam hasil uji hipotesi keempat, Green promotion berpengaruh positif dan namun tidak signifikan terhadap minat beli konsumen, maka hipotesis keempat tidak didukung. Hal ini bertolak belakang dengan hasil penelitian sebelumnya (Mahmoud, T. O., Ibrahim, S. B., Ali, A. H., \& 
Bleady, 2017); (Musa et al., 2020) yang menyatakan bahwa green promotion berpegaruh positif dan signifikan terhadap minat beli konsumen. Dapat diartikan bahwa konsumen Love Beauty and Planet di Jakarta memiliki minat dalam membeli produk yang tidak dipengaruhi oleh promosi-promosi yang dilakukan oleh Love Beauty and Planet.

\section{Kesimpulan}

Berdasarkan hasil pengujian, analisis, dan pembahasan yang telah dijelaskan, maka kesimpulan penelitian ini adalah sebagai berikut: 1) Green Product berpengaruh positif dan signifikan terhadap minat beli konsumen Love Beauty and Planet di Jakarta. 2) Green Price tidak berpengaruh positif signifikan terhadap minat beli konsumen Love Beauty and Planet di Jakarta. 3) Green Place berpengaruh negatif dan tidak signifikan terhadap minat beli konsumen Love Beauty and Planet di Jakarta. 4) Green Promotion berpengaruh positif namun tidak signifikan terhadap minat beli konsumen Love Beauty and Planet di Jakarta. 


\section{BIBLIOGRAFI}

Arslan, Muhammad, \& Zaman, Rashid. (2015). Impact of Brand Image and Service Quality on Consumer Purchase Intentions. A Study of Retail Stores in Pakistan. GRIN Verlag.Google Sholar

Hashem, Tareq N., \& Al-Rifai, Nahla A. (2011). The influence of applying green marketing mix by chemical industries companies in three Arab States in West Asia on consumer's mental image. International Journal of Business and Social Science, 2(3). Google Sholar

Karunarathna, A. K. P., Bandara, V. K., Silva, A. S. T., \& De Mel, W. D. H. (2020). Impact of Green Marketing Mix on Customers' Green Purchasing Intention with Special Reference to Sri Lankan Supermarkets. Google Sholar

Kumar, Prashant, \& Ghodeswar, Bhimrao M. (2015). Factors affecting consumers' green product purchase decisions. Marketing Intelligence \& Planning. Google Sholar

Mahmoud, T. O., Ibrahim, S. B., Ali, A. H., \& Bleady, A. (2017). The influence of green marketing mix on purchase intention: The mediation role of environmental knowledge. International Journal of Scientific \& Engineering Research, 8(9), 1043. Google Sholar

Mahmoud, T. O. (2019). Green marketing: A marketing mix concept. International Journal of Electrical, Electronics and Computers, 4(1), 20-26. Google Sholar

Musa, Haslinda, Mansor, N., \& Musa, H. (2020). The Influence of Green Marketing Mix on Consumer Purchase Intention Towards Green Products. International Journal of Human and Technology Interaction (IJHaTI), 4(1), 89-94. Google Sholar

Pathak, Dhanjit. (2017). Role of Green Marketing in Satisfying the Customers and Its Impact on Environmental Safety. International Research Journal of Interdisciplinary \& Multidisciplinary Studies (IRJIMS), 2(12), 17-29. Google Sholar

Penitasari, Nurul. (2017). Pengaruh Harga dan Kualitas Produk terhadap Minat Beli Abon Lele Bang Zay (Studi pada Konsumen Abon Lele Bang Zay di Kota Malang). University of Muhammadiyah Malang. Google Sholar

Phillip, Kotler, \& Keller, Kevin Lance. (2012). Marketing Management 14th edition Jakarta: PT. Indeks Kelompok Gramedia. Google Sholar

Queensland Government. (2002). Green Marketing- The Competitive Advantage of Suistainability. www.epa.qld.gov.au/sustainable_industries.

Rahbar, Elham, \& Wahid, Nabsiah Abdul. (2011). Investigation of green marketing 
tools' effect on consumers' purchase behavior. Business Strategy Series. Google Sholar

Shil, P. (2012). "Evolution and future of environmental marketing”, Asia Pacific Journal of Marketing and Management Review, Vol. 1 No. 3, pp. 74-81.

Tiwari, Sandeep, Tripathi, Durgesh Mani, Srivastava, Upasana, \& Yadav, P. K. (2011). Green marketing-emerging dimensions. Journal of Business Excellence, 2(1), 18. Google Sholar

Wang, Y.-H., Chen, S.-T., \& Chen, N.-N. (2016). An Empirical Study of the Effect of Green Marketing on Purchase Intention :Evidence from Green Restaurant. 9-11. Google Sholar

Copyright holder :

Dwi Oktaviani dan Rodhiah (2021)

First publication right :

Syntax Idea

This article is licensed under:

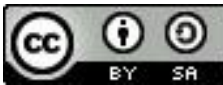

